\section{Dr. Harsh K. Gupta}

\section{IUGS Councilor}

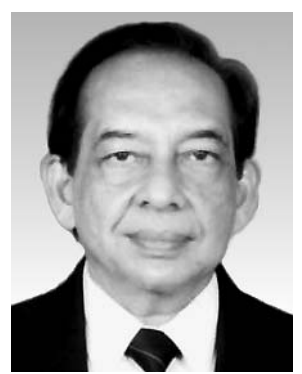

Born on June 28, 1942 in Moradabad (U.P.), India, Dr. Harsh Gupta had his education at the Indian School of Mines (B.Sc. (Hons), M.Sc. and A.I.S.M) and University of Roorkee (PhD). He availed two years UNESCO fellowships for advanced studies at Tokyo. In 1969, he married Manju Gupta. They now have two grown-up daughters. Currently Dr. Gupta is a Secretary to Government of India looking after the Department of Ocean Development. The important positions he held earlier include Director, Centre for Earth Science Studies, Trivandrum (1982-87); Vice-Chancellor, Cochin University of Science \& Technology (1987-90); Adviser, Department of Science \& Technology, Government of India, New Delhi (1990-92) and Director, National Geophysical Research Institute, Hyderabad (1992-2001). Earlier he was a Research Scientist at the University of Texas at Dallas (1972-77) and has been an Adjunct Professor since 1977. Dr. Harsh Gupta has specialized in Earth Sciences and their application to address problems of continents and oceans, administration of educational and scientific institutions. Dr Gupta has published over 130 research papers in international journals, written 3 pioneering books published by Elsevier Scientific Publishing Company, Amsterdam and edited over 15 volumes. His first book "Dams and Earthquakes" has been translated in Russian and Chinese.

Dr. Gupta provided the first geophysical evidence for an enormously thick crust $(65-70 \mathrm{~km})$ below the Tibet Plateau and Himalayan region in 1967, found to be accurate as confirmed by detailed field seismic surveys conducted in 1980s. Over the past 35 years, his detailed studies of earthquake focal mechanism, surface wave attenuation and other related work threw much light on the geodynamic processes responsible for the high elevation of Tibet Plateau and tectonics of the Himalaya and nearby region.

Harsh Gupta pioneered investigations of artificial reservoirinduced earthquakes and developed criteria to discriminate reservoir-induced earthquakes from normal earthquakes. These criteria are now internationally applied. Dr. Gupta also developed procedures to estimate potential of occurrence of reservoir-induced earthquakes at a given site. Dr. Gupta completed a detailed study in 1986 of earthquake swarms and quiescence that precede major earthquakes in the northeast India region and concluded that major earthquakes are preceded by well-defined swarms and quiescence. $\mathrm{He}$ made a medium term forecast of an $8 \pm 1 / 2$ magnitude earthquake to occur in area bound by $21^{\circ} \mathrm{N}$ and $25^{\circ} \mathrm{N}$, and $93^{\circ} \mathrm{E}$ and $96^{\circ} \mathrm{E}$ with a focal depth of $100 \pm 40 \mathrm{~km}$ before the end of 1990. This has come true.

Dr Gupta has carried out detailed studies of Latur earthquake, the deadliest stable continental region earthquake, and shown that fluids existing at shallow crustal depths played an important role in the genesis of the earthquake. Very recently he has developed the concept of spectral magnitudes and showed its application in learning about characteristics of seismic sources using broadband recordings. One latest application has been in characterizing the nuclear explosion. From 1992 to 1999, he was the Chairman of the Steering Committee for the Global Seismic Hazard Assessment Programme (GSHAP), which involved about 500 scientists from around the world, working for seven years to produce an internationally acclaimed GSHAP map.

Dr Harsh Gupta has been very deeply involved with investigations related to oceans. Early in his career during 1964-65 he participated in the India Ocean Expedition Programme where joint expeditions were undertaken in the Arabian Sea by the German research vessel Meteor and Indian research vessel Kistna. In 1968, he carried out very detailed investigations of regional crustal structure of the Bay of Bengal and Arabian Sea using the state-of-the-art surface wave dispersion techniques. Later, as the Director of Centre for Earth Science Studies (1982-87), Trivandrum, he pioneered efforts to generate wave atlas of the west coast of India. Detailed work on placer deposits on the west coast was also carried out.

He was leader of the 3rd Indian Scientific Expedition to Antarctica (1983-84) which established a permanent base for India in a record time. This station fulfilled a very urgent scientific requirement of the country. One of the major requirements in Antarctica has been the setting-up of a permanent seismic station as well as permanent GPS station. Under Dr Gupta's stewardship, these two major objectives were achieved during 1996-97 and 1997-98.

In recent years, at the National Geophysical Research Institute, he has initiated a very detailed work on gas hydrates in the Exclusive Economic Zone of India. A comprehensive report has been prepared under his leadership entitled "Gas Hydrate Exploration along the Continental Margins of India - Evaluation of Available Geophysical and Geological Data". Another landmark work has been the analysis of 80,000 line $\mathrm{km}$ of single channel seismic data in the Indian Exclusive Economic Zone to identify locations where bottom simulating reflectors occur. This has been extremely helpful in identifying zones of gas hydrate occurrences.

Dr. Gupta has been very active internationally. He is the founder President of Asian Seismological Commission, Bureau Member of the International Union of Geodesy and Geophysics (IUGG) and Councilor of the International Union of Geological Sciences (IUGS). Earlier, he was the Chairman of IASPEI/ UNESCO/ICL Working Group on Seismology and Related Sciences in Africa as well as Bureau Member and Chairman of several committees of the International Lithosphere Programme. He has convened several international symposia at IUGG, IASPEI and IGU Assemblies. During January 1998, he convened a Chapman Conference on "Stable Continental Region Earthquakes" at NGRI, Hyderabad.

Dr. Gupta has been a visiting Professor at University of Paris Sud, Paris, France; University of Texas at Dallas, USA and University of Hamburg, Germany. He has also been a visiting scientist at US Geological Survey and Adviser/Consultant to UNESCO, IAEA and Commonwealth Science Council on several occasions.

Dr. Gupta has won several awards during his scientific career. These include: "Shanti Swarup Bhatnagar Prize" for S\&T in Earth Sciences (1983); USSR Academy of Sciences' "100 Years of International Geophysics" Memorial Medal (1985); National Mineral Award (1991); Second Outstanding Performance Award by the 11th International Kharazmi Festival of Iranian Research Organization for Science \& Technology, Tehran, Iran (1998); Federation of Indian Chamber of Commerce and Industry Award (1999) and the Indian Geophysical Union Millennium Award (2000).

\author{
Address: \\ Dr. Harsh K. Gupta \\ Secretary to the Government of India \\ Department of Ocean Development, \\ Mahasagar Bhavan, \\ Block-12, CGO Complex, \\ New Delhi-110003, \\ INDIA \\ Tel: 91-11-4360874, 4362548 \\ Fax: 91-11-4362644 \\ E-mail: dodsec@dod.delhi.nic.in
}

